Scientiæ studia, São Paulo, v. 10, n. 4, p. $77^{3-98,2012}$

\title{
त्री \\ A contribuição brasileira de Alcindo Flores Cabral à classificação periódica dos elementos
}

\author{
Juergen Heinrich MAAR \& Eder João LenARDÃo

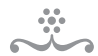

RESUMO

Este artigo apresenta a contribuição de Alcindo Flores Cabral (1907-1982) - professor de química da Faculdade de Agronomia Eliseu Maciel, hoje incorporada à Universidade Federal de Pelotas - ao ensino de química, uma contribuição quase desconhecida pela própria comunidade química brasileira, embora reconhecida como relevante por diversos químicos estrangeiros importantes, como W. Hückel, G. Charlot, F. Strong, E. Fessenden e outros. A inovadora representação helicoidal de Cabral é apresentada não só em conexão com representações contemporâneas, mas também inclui-se uma incursão pelos primeiros sistemas helicoidais propostos, os de Hinrichs e de Baumhauer. Apresentam-se alguns comentários não somente sobre a Classificação natural dos elementos, publicada em 194,6, mas também sobre outros textos escritos para tornar mais eficaz o ensino de química.

Palavras- Chave • Tabela periódica. Classificação natural dos elementos. História da química no Brasil. Cabral.

\section{INTRODUÇÃO}

A classificação periódica dos elementos, ou, se preferirmos, o sistema periódico dos elementos, é sem dúvida, nas palavras do historiador Eric Scerri,

um dos mais poderosos ícones na ciência: um único documento que consolida muito de nosso conhecimento sobre química (...) apesar das dramáticas mudanças que ocorreram na ciência nos últimos cem anos - a saber, o desenvolvimento das teorias da relatividade e da mecânica quântica - não houve revolução na natureza básica da tabela periódica (Scerri, 1998, p. 78).

Ainda no entender de Scerri, a classificação periódica não é fruto do brainstorm de um indivíduo particular, trata-se muito mais do ponto culminante de um grande número de desenvolvimentos científicos, devidos a muitos químicos (cf. Scerri, 1998, p. 79). 
Para o historiador holandês Johannes Willem van Spronsen. É preciso considerar três períodos na história do sistema periódico (cf. Spronsen, 1969):

- o período dos precursores (1817/1862);

- o período da descoberta do sistema (1862/1871);

- o desenvolvimento posterior a 1871 .

Em cada um desses períodos, a abordagem do problema da "classificação periódica" dos elementos está inserida no pensamento filosófico dominante no período em tela. Assim, no período dos precursores, observam-se inicialmente relações numéricas formuladas a priori, que indicam uma periodicidade, como nas propostas de Richter ou de Dumas. A essas relações soma-se o estudo de analogias, tão característico da Naturphilosophie da primeira metade do século xIx, visíveis, por exemplo, nas classificações de Döbereiner (1817) ou de Gmelin (1842), e a ideia de unidade, igualmente característica da Naturphilosophie, particularmente presente nas propostas que partem de um "elemento primordial" (hidrogênio, ou o "protilo"), que está na base de todas as classificações anteriores a Mendeleiev. Algumas dessas tabelas precursoras fazem uso, para classificar os elementos, de certas propriedades, por exemplo, a reatividade dos elementos frente ao oxigênio, adotada por Thénard em sua classificação dos metais. Para Ampère, tais classificações baseadas em analogias, nem sempre fáceis de perceber, seriam muito pragmáticas, ou artificiais, por serem baseadas em critérios elaborados a partir de dados teóricos e empíricos, e propõe que se adote uma classificação natural (cf. Bertomeu-Sanchez et al., 2002, p. 227). Dumas define da seguinte maneira uma classificação natural dos elementos:

por classificação natural eu entendo uma disposição de corpos em grupos, com base em características suficientemente importantes para considerá-las capazes de determinar todas as propriedades secundárias. Essas características são os vários modelos de combinação de compostos, sua capacidade calorífica e seu volume atômico no estado sólido (Dumas apud Bertomeu-Sanchez et al., 2002, p. 245).

Avançando em duas frentes (analogias e relações numéricas) chega-se aos poucos a um "sistema" representado por uma "classificação periódica". O sistema periódico dos elementos, atribuído geralmente pela tradição historiográfica a Mendeleiev e independentemente a Lothar Meyer, pode, segundo Spronsen (1959, p. 565) ser atribuído a seis descobridores independentes: Chancourtois, Newlands, Odling, Hinrichs, Meyer e Mendeleiev. 
A gontribuição brasileira de Algindo Flores Gabral...

\section{O SISTEMA PERIÓDICO}

A tabela periódica clássica de Mendeleiev, modificada no que foi necessário, sobreviveu incólume, em linhas gerais, a todas as mudanças surgidas com a moderna física, como a descoberta da radioatividade, dos gases nobres, a substituição dos pesos atômicos pelos números atômicos depois dos estudos de Moseley etc.

No que se refere à sobrevivência diante de novas tendências filosóficas, e considerando todas as mudanças físicas que não afetam o sistema periódico dos elementos, podemos invocar a teoria dos sistemas, entendendo por "sistema" uma totalidade de elementos, ${ }^{\mathbf{1}}$ delimitados arbitrariamente dos elementos do meio externo. Os elementos de um sistema relacionam-se uns com os outros, com a totalidade e com os elementos externos, e essas relações podem ser descritas em termos de grandezas que chamamos de "variáveis". A teoria dos sistemas considera dois tipos de variáveis, interessando-nos aqui variáveis deterministas que admitem uma só interpretação. Elementos sistêmicos são aquelas partes do sistema que intermedeiam variáveis que se correspondem, embora não seja possível indicar os limites físicos dessas partes. Essas variáveis são essenciais como base para a descrição do sistema, e leis teóricas sistêmicas descrevem a maneira pela qual se relacionam as variáveis sistêmicas. As variáveis sistêmicas são obrigatoriamente causais, podendo ser matematizadas, mas não resolvidas, como função de variável independente. Chamamos de "modelos" todas as representações dos aspectos tidos como essenciais do sistema e, como podemos, em função de nossas finalidades, escolher esses aspectos essenciais, há diversos modelos para os sistemas. Os modelos são empírico-técnicos (o modelo atômico-molecular), ou cognitivo-formais (paradigmáticos, como ideologias; relativos, como fluxogramas), ou ordenativos, como o sistema periódico dos elementos. Chamamos de "modelos sistêmicos" aqueles que descrevem a atuação conjunta das variáveis tidas como essenciais na forma de um registro gráfico ou de uma expressão matemática (cf. Hirsig, 1994).

O uso do conceito de "sistema" supera as muitas definições do tipo círculo vicioso com que os químicos e historiadores frequentemente abordam o tema da "classificação periódica”. Por exemplo, Ralph Cahn, em uma obra recente na qual analisa os pressupostos filosóficos (em um viés bachelardiano, pois a tabela periódica é tomada como uma "construção" que seria, por sua vez, uma "representação rudimentar" baseada em dados empíricos) e historiográficos da tabela periódica, chega a dizer que o assunto "tabela periódica" não interessa aos químicos, e que "desde que existem os sistemas periódicos [químicos] ficou claro o que são sistemas periódicos” (Cahn, 2002, p. 5).

1 Não se trata, nessa definição, de elementos químicos, mas de elementos no sentido geral de "partes". 
O conceito de "sistema periódico" dos elementos também valoriza as diferentes formas de registros gráficos da classificação periódica dos elementos químicos, dos quais Mazur informa existirem mais de 700 (cf. Mazur, 1974). Pois a persistência do sistema de Mendeleiev, apesar de todas as inovações surgidas na física e na química, faz com que mudem meramente os registros gráficos da classificação dos elementos, para que se possam incorporar à mesma novidades como as terras raras finalmente caracterizadas, os gases nobres, os elementos artificiais e os transurânicos e transférmicos. Com relação aos registros gráficos, Ihde (cf. 1984, p. 252-5) considera todas as tabelas periódicas posteriores a Mendeleiev como pertencendo a um dos quatro seguintes tipos:

- as tabelas curtas (o arquétipo é a própria tabela de Mendeleiev);

- as tabelas longas (desenvolvidas para incluírem de forma ordenada as terras raras e separar os subgrupos);

- as tabelas helicoidais ou em espiral;

- as tabelas tridimensionais.

A persistência da classificação periódica de Mendeleiev como um modelo ordenativo para os elementos químicos é certamente resultado da combinação nela existente de uma sistematização dos elementos conhecidos no tempo de Mendeleiev, e de uma capacidade preditiva em relação a elementos ainda desconhecidos. Essa capacidade preditiva permitiu à classificação de Mendeleiev incorporar a descoberta de novos elementos, para os quais a classificação e sua representação gráfica previram espaços (os exemplos clássicos são os elementos gálio, escândio e germânio), a incorporação de novos grupos de elementos, como os gases nobres (todos descobertos no período 1894/1898) ou a reordenação de um grupo inteiro de elementos, os elementos das terras raras (descobertos em sua maioria depois da proposta de Mendeleiev).

Como o modelo ordenativo de Mendeleiev parte de dados experimentais sobre os elementos e seus compostos - no interior de uma postura positivista pouco ortodoxa e bastante atenuada -, sua classificação periódica é construída a posteriori a partir de dados empíricos. As propriedades químicas e físicas podem ser encaradas como as variáveis deterministas que levarão ao ordenamento sistêmico que encontra representação em um modelo que é a tabela periódica de Mendeleiev. A tabela era inicialmente vertical, depois passou a ser horizontal, mas o que importa mesmo é o ordenamento. A tabela periódica de Mendeleiev mostrou-se particularmente até os dias de hoje (com as devidas atualizações, é claro), e não sucumbiu diante de modificações radicais que seriam fatais para outras representações, como a substituição dos pesos atômicos pe- 
los números atômicos como característica fundamental do elemento, justamente por ser uma construção a posteriori a partir de dados empíricos servindo de variáveis sistêmicas e que, no caso dos elementos e seus compostos, são causais, porque determinam situações posteriores.

Sendo um sistema periódico construído a posteriori, a classificação de Mendeleiev não cria um círculo vicioso, como o vê - para nós, equivocadamente-Cahn, para quem o sistema periódico é como que uma visão coletiva dos elementos ordenados de dada maneira que corresponde a uma intuição. Mesmo quando se consideram as grandezas e qualidades dos elementos como permanentes e já existentes, antes de ter-se dos elementos uma visão ordenada, um sistema a posteriori como o de Mendeleiev supera os ordenamentos a priori de seus precursores, como os ordenamentos de Döbereiner e de Gmelin.

\section{As TABELAS EM ESPIRAL}

As tabelas tradicionais curtas ou longas tornam evidentes as periodicidades segundo colunas (verticais) e séries (horizontais). Mas não se esgota nessas relações a periodicidade, razão pela qual foram sugeridas desde cedo certas relações diagonais. As tabelas helicoidais ou em espiral procuram dispor os grupos de elementos de uma forma que deixe mais explícitas relações não visíveis nos registros tradicionais (ver as figuras 1 e 2). O mais antigo de tais sistemas em espiral é o de Detlev Hinrichs (1836-1923), um teuto-dinamarquês ativo nos Estados Unidos, que ironicamente ocupou-se com a classificação dos elementos, embora não acreditasse em uma periodicidade (cf. Zappfe, 1969). A contribuição de Hinrichs não teve repercussão, e a literatura científica do século xIX registra como primeira classificação em espiral (1870) a de Heinrich Adolf Baumhauer (1848-1926), professor na universidade de Friburgo, na Suíça. Baumhauer utiliza decididamente a sequência de pesos atômicos na disposição dos elementos, percebendo-se as analogias e as relações pelo menos nos grupos mais importantes de elementos (ver a figura 2). A espiral foi dividida em 7 partes, numeradas de I a VII, cada qual contendo um grupo de elementos análogos ( $\mathrm{I}$ = halogênios; II = metais alcalinos etc.). 


$\begin{array}{lll}\text { Ano } & \text { Proponente } & \text { Ativo em } \\ 1867 & \text { Detlev Hinrichs }(1836-1923) & \text { Iowa City/EU } \\ 1870 & \text { Heinrich Baumhauer }(1848-1926) & \text { Freiburg/Suíça } \\ 1871 & \text { Julius Quaglio }(1833-1899) & \text { Munique } \\ 1888 & \text { G. Johnstone Stoney }(1826-1911) & \text { Dublin } \\ 1902 & \text { Hugo Erdmann }(1862-1910) & \text { Halle } \\ 1928 & \text { Charles Janet }\left(1849^{-1932)}\right. & \text { Paris }\end{array}$

Tabela 1. Primeiras classificações periódicas em espiral

Outra tabela em espiral, mais detalhista que a de Baumhauer, é a de Julius Quaglio (1833-1899), químico e tecnólogo ativo em Munique (cf. Renatus, 1983). As espirais logarítmicas de Johnstone Stoney, publicadas em 1888 e em 1902, mostram alguma inovação, mas não cabe aqui comentar todas essas classificações.

\section{UMA GONTRIBUIÇÃO BRASILEIRA}

Até onde é de nosso conhecimento, a primeira contribuição brasileira ao desenvolvimento da classificação periódica é o trabalho de 194,6, intitulado Classificação natural dos elementos, do professor Alcindo Flores Cabral (1907-1982). Praticamente desconhecida hoje na literatura científica internacional, e mesmo na literatura química brasileira, talvez pela forma pouco convencional pela qual o professor Cabral divulgava suas ideias, e certamente por atuar em local distante dos centros principais de criação científica. Também em nosso país pouco se sabe dessa contribuição ao sistema periódico, pois quando ela foi apresentada à comunidade científica brasileira tratava-se também de ciência vinda de fora dos centros mais importantes da pesquisa química. $O$ fato de Cabral não ser químico, e o de ter lecionado química em uma escola de agronomia, cujos egressos pouco interesse deveriam ter tido para dedicarem-se futuramente à ciência da matéria, certamente contribuíram para a pouca divulgação de sua obra. A Classificação natural dos elementos (194,6), do engenheiro-agrônomo Alcindo Flores Cabral, ex-catedrático de química analítica da Escola de Agronomia Eliseu Maciel, ${ }^{2}$

2 Criada em 1883 como Imperial Escola de Medicina Veterinária e de Agricultura Prática (a segunda mais antiga do Brasil), passou a denominar-se, em 1890, Liceu Riograndense de Agronomia e Veterinária, com status de curso superior, recebendo, em 1926, o nome de Escola de Agronomia e Veterinária Eliseu Maciel. Os cursos de agronomia e veterinária tornaram-se cursos independentes em 1934. Federalizada em 1945, a Escola foi incorporada, em 1969, à Universidade Federal de Pelotas. As terras em que se criou a Escola pertenceram à família do conselheiro Eliseu Antunes Maciel (cf. Magalhães, 1996). 
A gontribuição brasileira de Algindo Flores Cabral...

hoje incorporada à Universidade Federal de Pelotas (FAEM/UFPEL), foi possivelmente a primeira descrição do arranjo periódico dos elementos químicos em uma forma atômica levando em consideração a distribuição eletrônica, inspirando o desenvolvimento de novas versões de sua tabela, mais elaboradas e publicadas posteriormente. Além desse trabalho, Cabral escreveu vários ensaios sobre química geral e química inorgânica, especialmente envolvendo ligações químicas e suas fundamentações teóricas. $\mathrm{O}$ presente trabalho pretende recuperar a história e a contribuição do professor Cabral para o ensino de química, surgida em uma época em que quase não se tomava conhecimento da produção brasileira no ensino de química. Não ilustramos nossos livros-texto, nossas aulas, nossas palestras, com o que aqui produzimos (cf. Leon Olivares, 2001). Desqualificar a Classificação natural dos elementos, caracterizando-a como tendo objetivos didáticos, seria um argumento que não encontra amparo na historiografia da química, pois tanto a classificação de Mendeleiev como a de Lothar Meyer foram criadas com fins confessadamente didáticos, como se encontram em seus respectivos livros-texto Princípios de química e As modernas teorias da química.

\section{Breve biografia de Algindo Flores Cabral}

Alcindo Flores Cabral (ver a figura da p. 772) nasceu em Tupanciretã-RS, em 10 de abril de 1907. Oriundo de família de agricultores, lidou no campo auxiliando seu pai até os 19 anos de idade. Em 1926, foi-lhe concedida pelo presidente do Estado do Rio Grande do Sul, Borges de Medeiros (1863-1961), a matrícula no Curso de Capatazes Rurais em Viamão-RS. ${ }^{3}$ Ingressou no curso preparatório, e obteve em 1928 o título de capataz rural, com medalha de honra. Foi contratado em seguida pela Diretoria de Agricultura do Rio Grande do Sul para atuar em Bagé, no sul do estado, onde permaneceu até 1934. Em 1936, estabeleceu-se em Pelotas, onde foi nomeado bromatologista no Serviço de Fiscalização e Padronização da Secretaria de Agricultura. Nesse posto, como encarregado das análises, permaneceu durante dez anos, fiscalizando a exportação de conservas alimentícias, de vinhos etc., e analisando também produtos de importação, como aguardente, álcool e erva-mate. Após retomar seus estudos e concluir o segundo grau no Colégio Municipal Pelotense (curso noturno, artigo 100), prestou vestibular e ingressou em 1941 na Escola de Agronomia Eliseu Maciel, diplomando-se engenheiro agrônomo em 1944, aos 37 anos. Seu desempenho ao longo do curso de graduação rendeu-lhe os prêmios Dr. Jorge Amaral Gomes de Freitas, Prêmio ao Mérito e Prêmio 
Dona Antônia. Ainda estudante de agronomia, Cabral reorganizou, desde 1943, o Gabinete de Química Analítica da Escola de Agronomia Eliseu Maciel e realizou análises, orientação e assistência que a Escola prestava na época aos agricultores, ao comércio e à indústria da região de Pelotas.

Em março de 1946, Cabral foi nomeado professor interino de química analítica da Escola de Agronomia Eliseu Maciel, sendo efetivado na cátedra de química analítica em 1949, aos 42 anos de idade, mediante aprovação em concurso público. Lecionou química durante 20 anos (de 1946 a 1966, quando se aposentou) e durante grande parte desse período foi o encarregado das análises de assistência à produção, até a instalação do Laboratório de Tecnologia do Instituto Agronômico do Sul. ${ }^{4}$ Em dezembro de 1977, foi inaugurada, no Departamento de Química Analítica e Inorgânica da Universidade Federal de Pelotas, a sala número 2, que recebeu o nome do Professor Alcindo Flores Cabral. Aos 74 anos de idade, em 29 de janeiro de 1982, o Prof. Cabral faleceu em Porto Alegre. Em 1999, a Câmara Municipal de Pelotas aprovou decreto que atribui o nome de "Professor Alcindo Flores Cabral" a uma rua da cidade.

\section{A produção do PROFessor Cabral}

Demonstrando uma capacidade incomum de aprender, interpretar e ir além dos conceitos de química desenvolvidos até a primeira metade do século passado, Alcindo Flores Cabral publicou, em 194,0, ano em que ainda se preparava para o vestibular de agronomia, o Ensaio de teoria eletrônico-molecular. Foi a primeira de uma série de publicações que buscavam desvendar os mistérios da química para os não químicos. O livro foi dedicado a seu sobrinho, com a seguinte apresentação:

Luís Ernesto, nós dois temos os olhos abertos para a contemplação do mundo, interrogando, cheios de admiração, a causa dos fenômenos. Naquele dia, tu com quatro anos e eu com oito vezes mais, estávamos juntos. Querias saber por que o fogo faz com que a água se evapore. Era justamente nisso que eu estava pensando, e eis aqui uma resposta, se bem que incompleta. Se há nela verdade é coisa que eu e tu saberemos quando fores grande (Cabral, 194,o, p. 4).

Em seu ensaio de pouco mais de dez páginas, Cabral aborda os fenômenos moleculares de mudança de estado físico em termos eletromagnéticos, sendo os pri-

4. O Instituto Agronômico do Sul foi criado em 194,3, instalado na Fazenda Gomes da Costa, e incorporou as estações experimentais de Ponta Grossa e Curitiba. 
meiros o "resultado do deslocamento de elétrons em órbitas do mesmo átomo provocado por propulsão molecular causada por campo eletro-negativo variável" (Cabral, 194 O, p. 9). Cabral sugere ainda que a ideia de "repulsão molecular" pode ser aplicada à condutividade elétrica, podendo explicar a razão do aumento de condutividade a temperaturas muito baixas.

Mais tarde, entre 1946 e 1953, Cabral publicou outros trabalhos, na forma de livros ou "boletins didáticos", destacando-se a Classificação natural dos elementos, cuja primeira edição foi publicada em julho de 1946, que será abordada adiante. Na área da agronomia, Cabral escreveu À margem do São Gonçalo, no qual descreve observações e transformações do ambiente próximo ao canal de São Gonçalo, que liga a Lagoa dos Patos à Lagoa Mirim, e Um agrônomo em viagem, relatando observações agrárias durante uma excursão ao Rio de Janeiro. Cabral preparou também um pequeno tratado de ciências naturais, "escrito para rapazes do meio rural".

Em novembro de 1953, foi publicada $A$ teoria de ácidos e bases de Arrhenius e as ideias modernas. Nesse trabalho, Cabral faz um relato resumido e bastante didático das teorias de acidez e de basicidade, sendo que as "ideias modernas" referidas no título do trabalho dizem respeito à teoria dos solventes de Edward Curtis Franklin (1862${ }_{19}{ }_{7}$ ) e às teorias de Brönstedt-Lowry e de Lewis hoje amplamente aceitas. Na conclusão de seu texto de pouco mais de 20 páginas, Cabral escreve o seguinte:

Entretanto, parece-nos que a análise feita nas páginas anteriores demonstra suficientemente que nenhuma definição essencial, generalizada, tem obtido êxito na explicação e coordenação completa dos ácidos e bases. E isso nos faz lembrar que a natureza constitue (sic) conjunto indiferenciado e harmônico, sendo a subdivisão e a classificação apenas um produto da mente humana (Cabral, 1953a, p. 19).

E mais adiante, Cabral sugere que apesar das falhas e limitações "nenhuma das concepções novas de ácidos e bases é capaz de aportar uma concatenação mais simples e de maior coerência aos fatos da química mineral [do que a teoria de Arrhenius]" (Cabral, 1953a, p. 20).

Cabral publicou ainda $A$ representação gráfica de alguns sistemas complexos de conexões atômicas, na qual é feita, segundo ele, a exposição de um sistema de fórmulas estruturais mais intuitivas e práticas. Nesse trabalho, escrito em 1952 e publicado em 1953, Cabral sugere o uso de novos sinais para mostrar ligações covalentes, valências e ligações coordenadas. Entretanto, sua principal preocupação foi desenvolver uma representação mais clara para as moléculas com duplas e triplas ligações que podem representar duas ou mais "estruturas de ressonância". Utilizando o que chamou de 


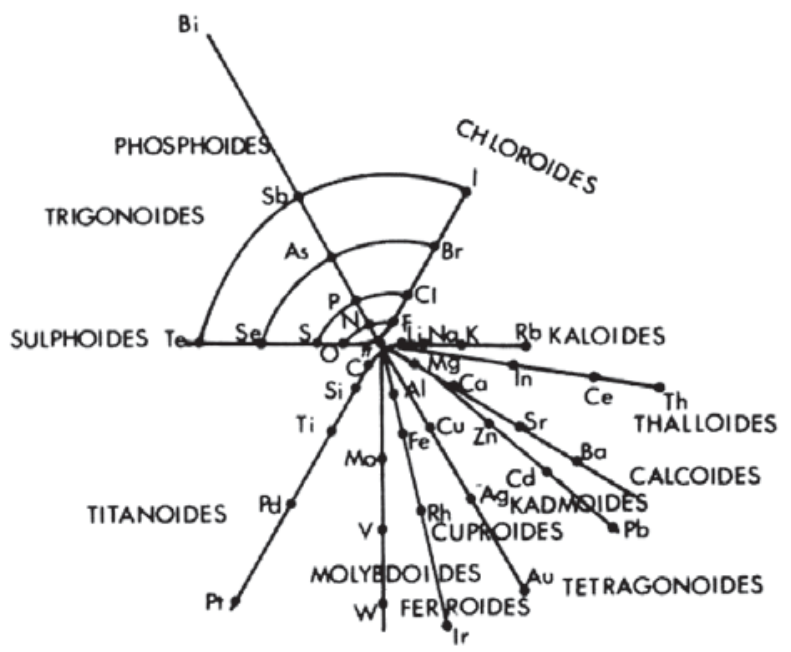

Figura 1. Tabela periódica proposta por Hinrichs.

(Figura cedida pela John Wiley/Verlag Chemie).

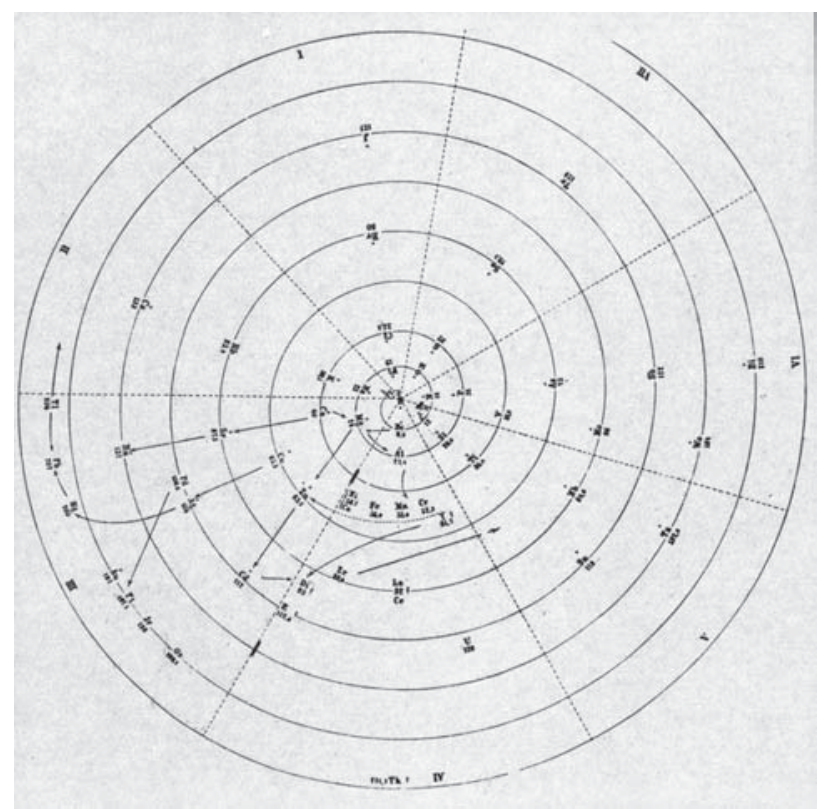

Figura 2. Tabela periódica proposta por Baumhauer.

(Figura cedida pela John Wiley/Verlag Chemie). 
A contribuição brasileira de Algindo Flores Cabral...
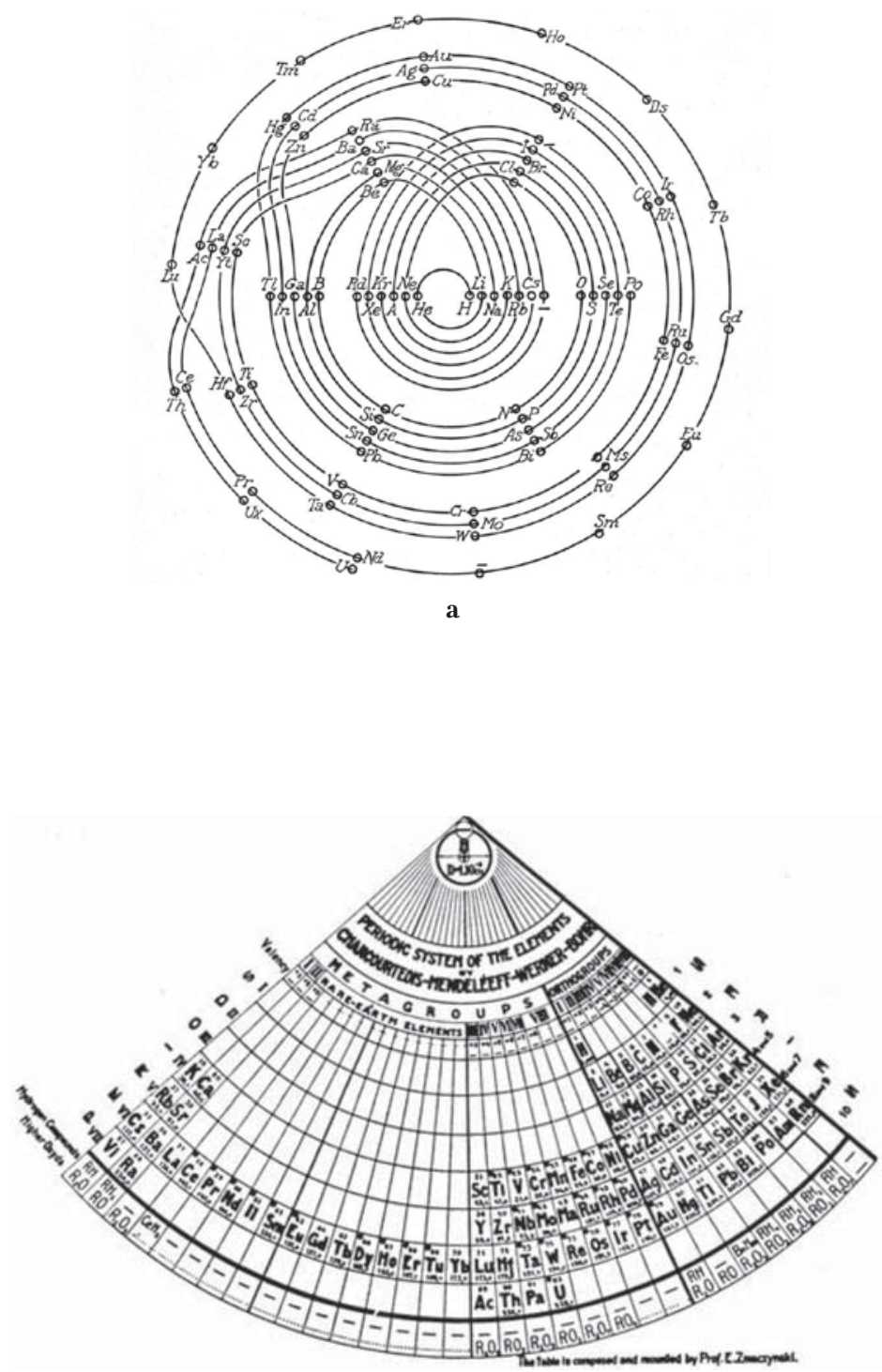

b

Figura 3. (a) A proposta de Monroe e Turner (1926) de uma nova tabela dos elementos; (b) a proposta de Zmaczynski ( ${ }^{19}{ }^{7} 7$ ) de uma nova forma para o sistema periódico dos elementos. 
Juergen Heinrich Maar \& Eder João Lenardão
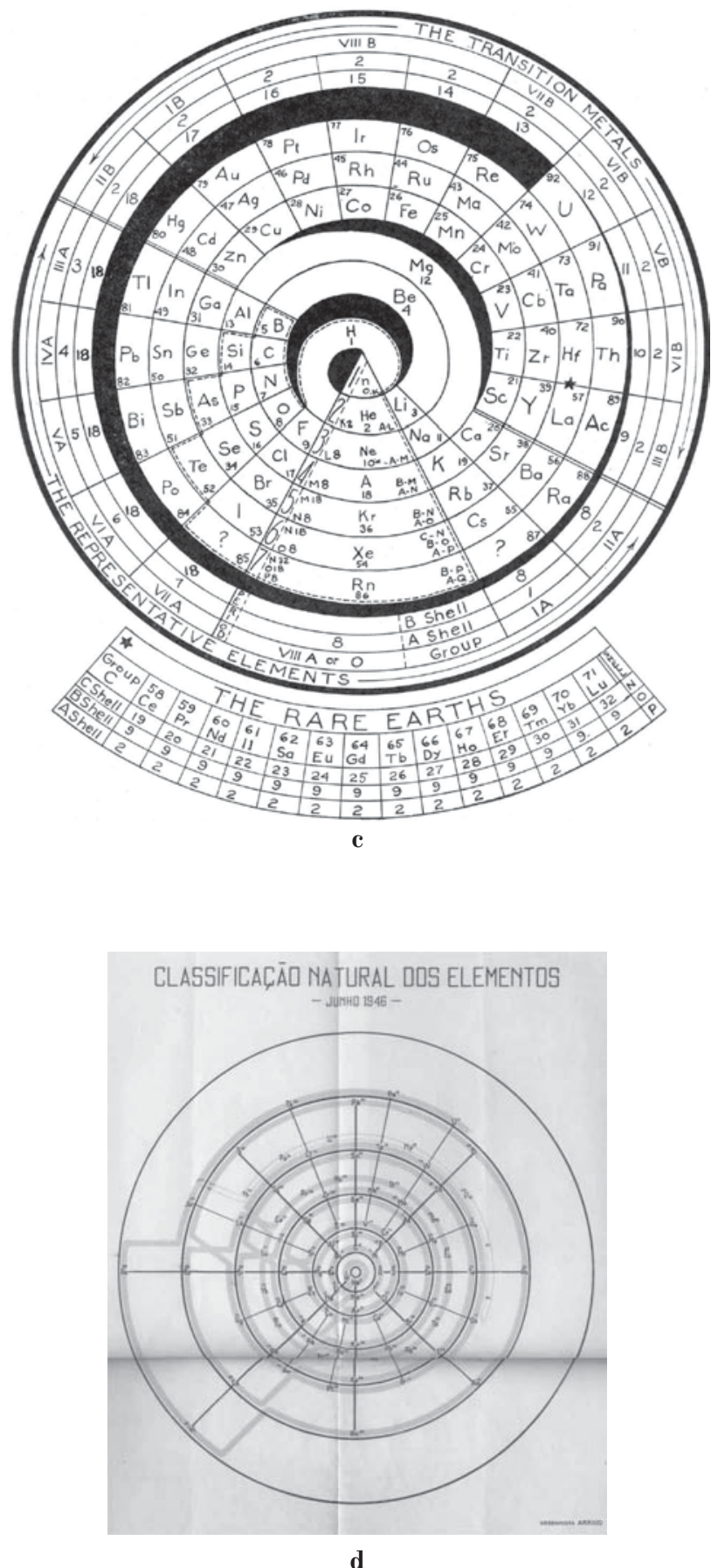

Figura 3. (c) A tabela espiral de Emerson (1944);

(d) primeira versão da tabela de Cabral (1946). 

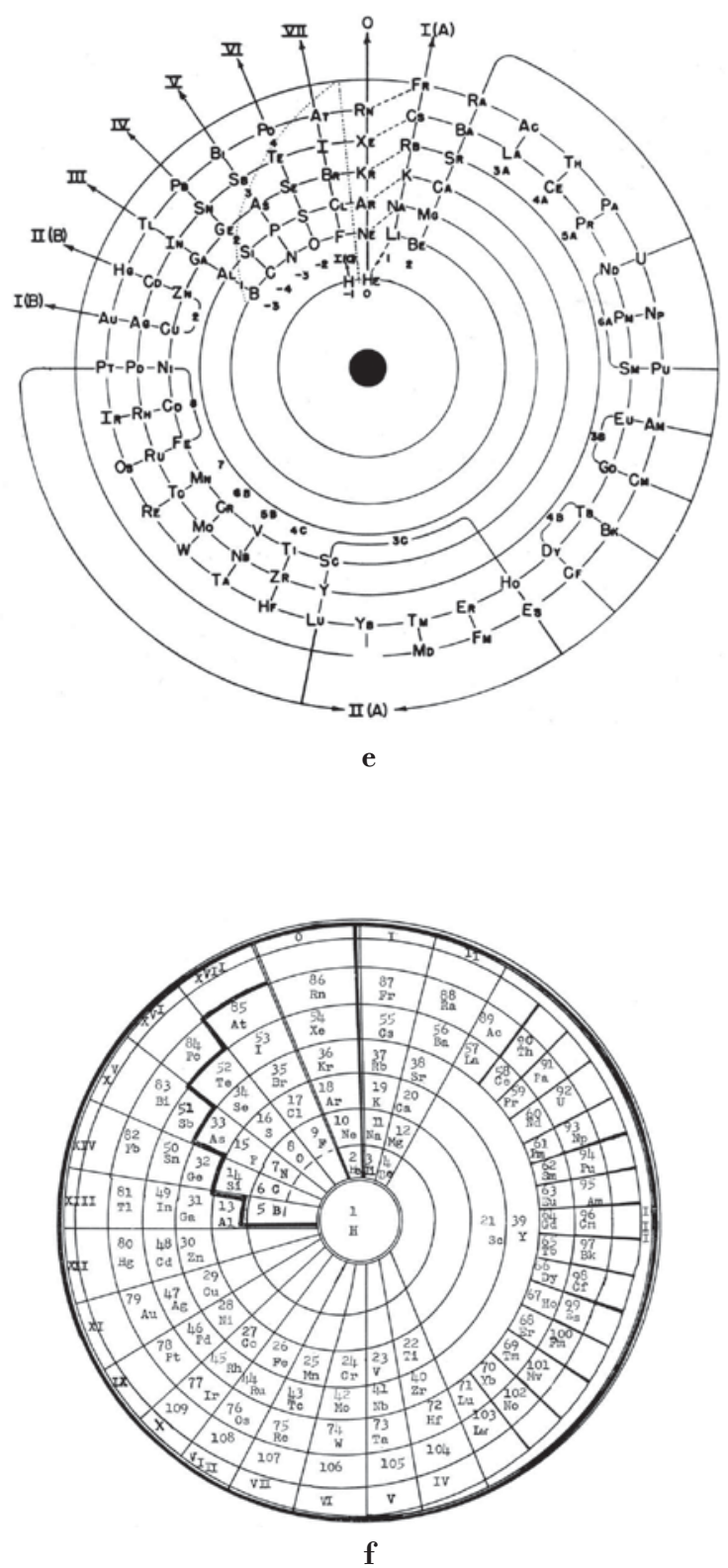

Figura 3. (e) A proposta de Strong (1959) de uma forma atômica para a tabela periódica; (f) a proposta de Griff (1964) de um sistema espiral para os elementos químicos. 
Tuinvivo dewerho
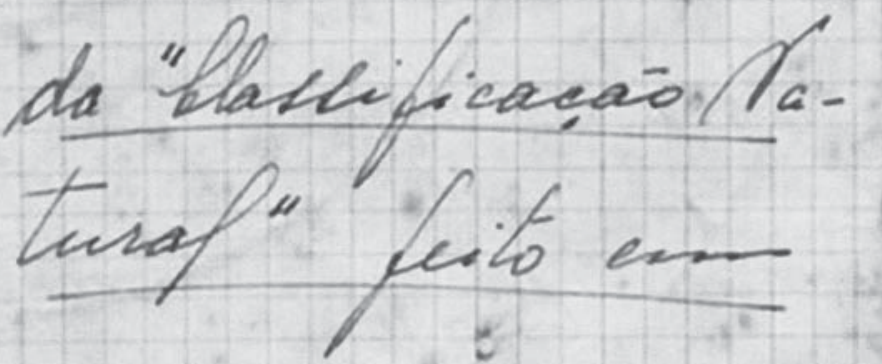

Tansico de $1946-$

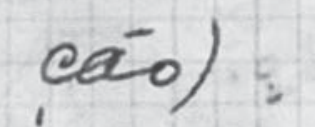

1

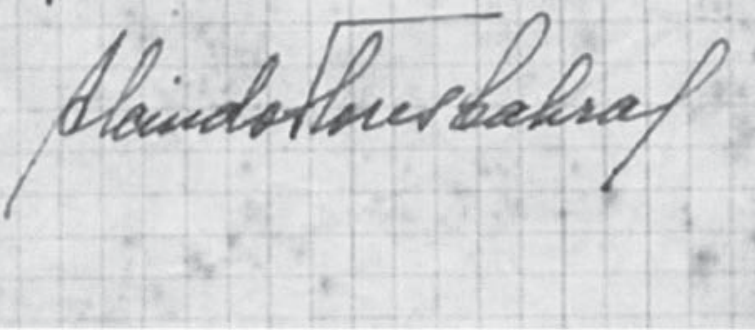

a
Juergen Heinrich Maar \& Eder João Lenardão

Figura 4. (a) Anotação no verso do primeiro desenho de 1946, mostrado na figura 3(d); (b) rascunho da segunda versão da Classificação natural dos elementos (cores diferentes para os subníveis s, p, d. f). (Fonte: $\mathrm{H}$. M. Cabral).

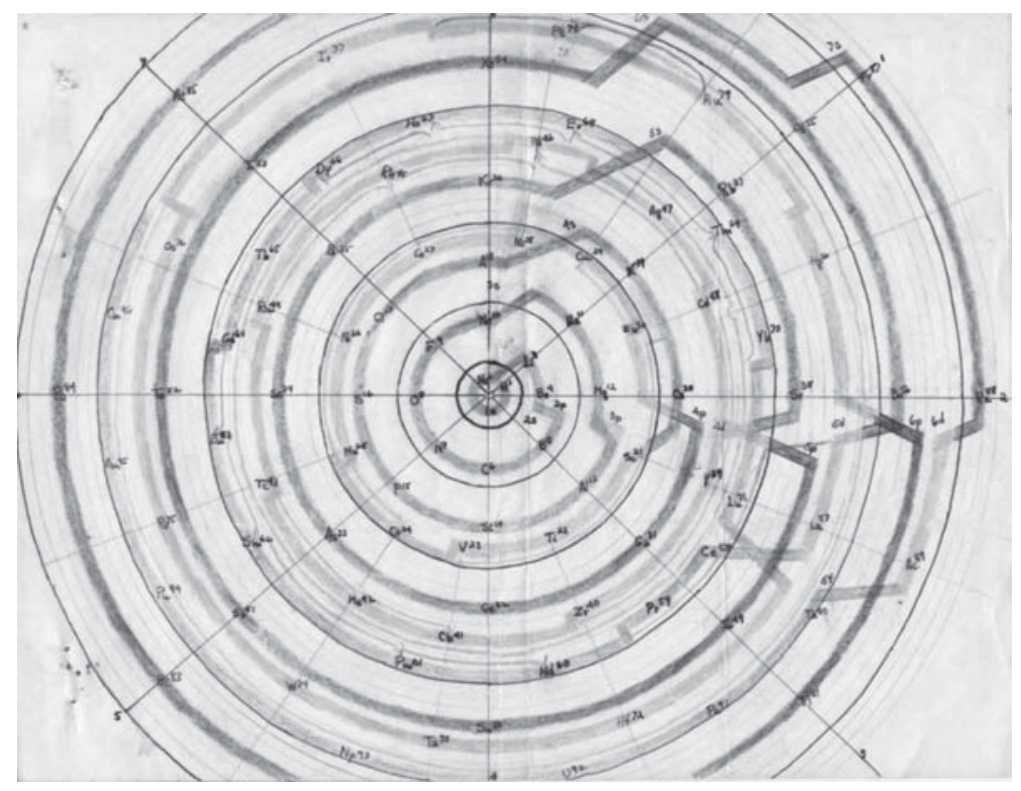


A gontribuição brasileira de Algindo Flores Gabral...

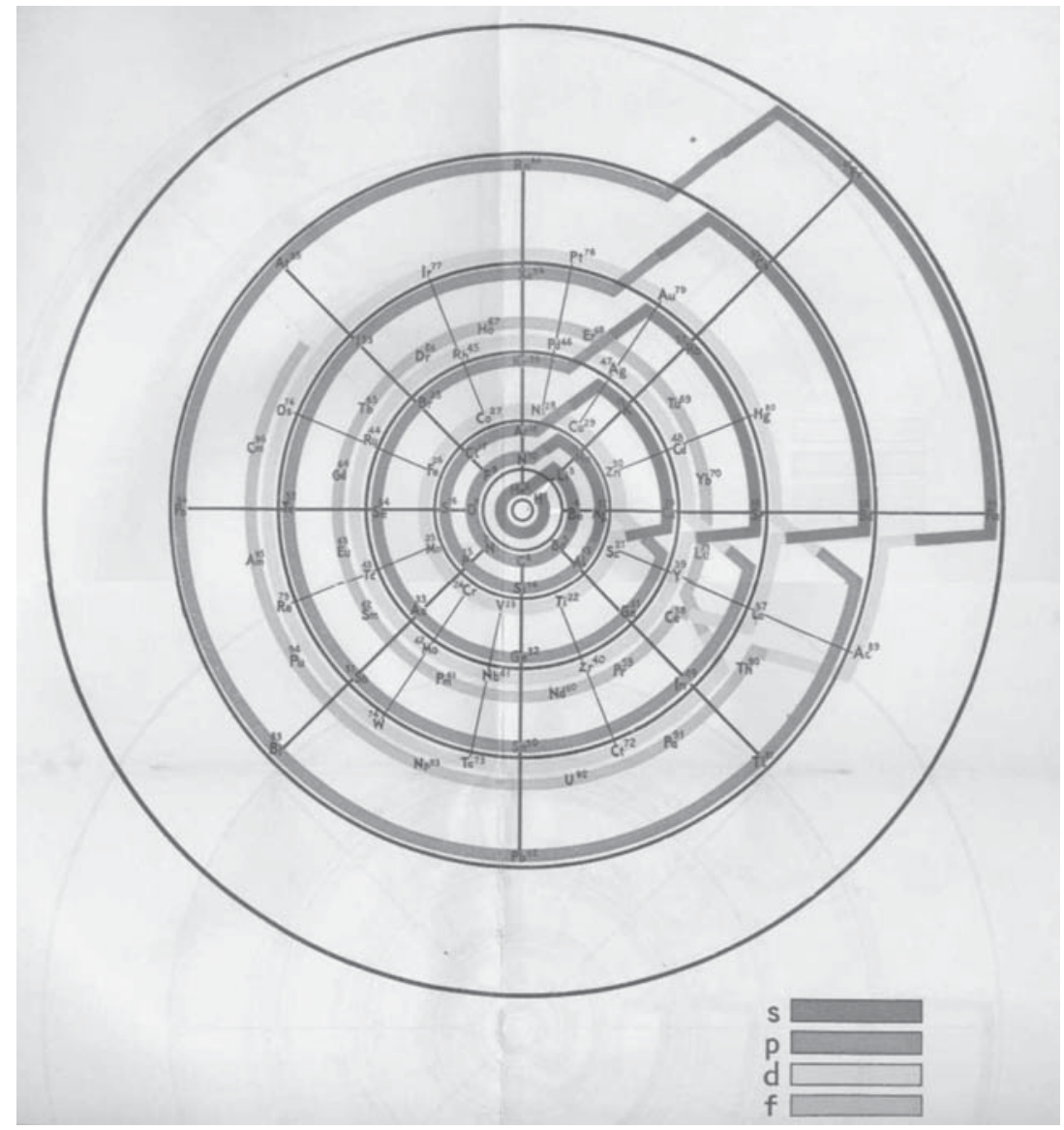

Figura 5. Versão final da Classificação natural dos elementos, que acompanhava o Boletim Didático No. 1 de 1951. 
Juergen Heinrich Maar \& Eder João Lenardão

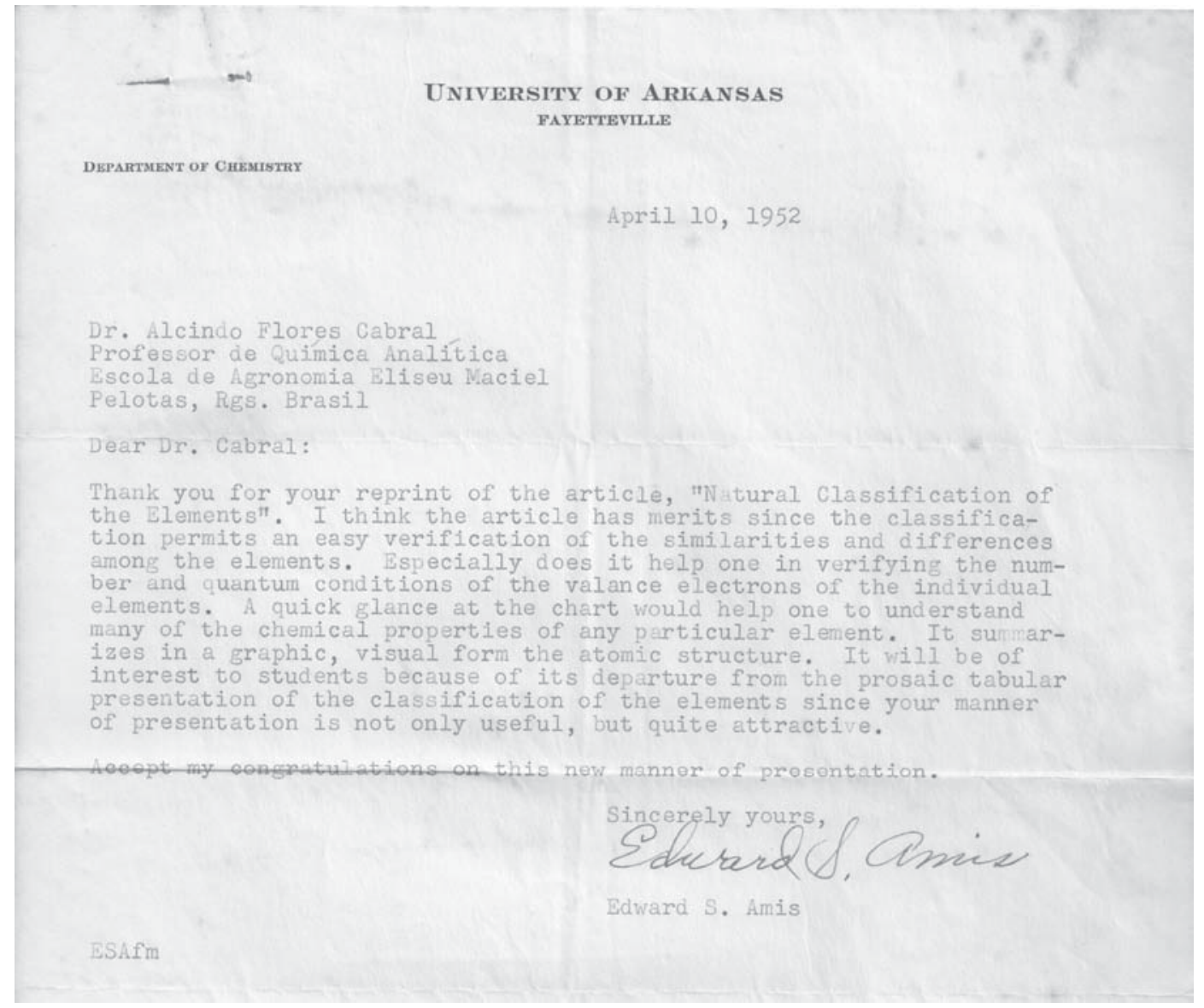

Figura 6. Agradecimento de Edward S. Amis, da Universidade de Arkansas, pelo envio da separata da Classificação natural dos elementos de Cabral. 
A gontribuição brasileira de Algindo Flores Gabral...

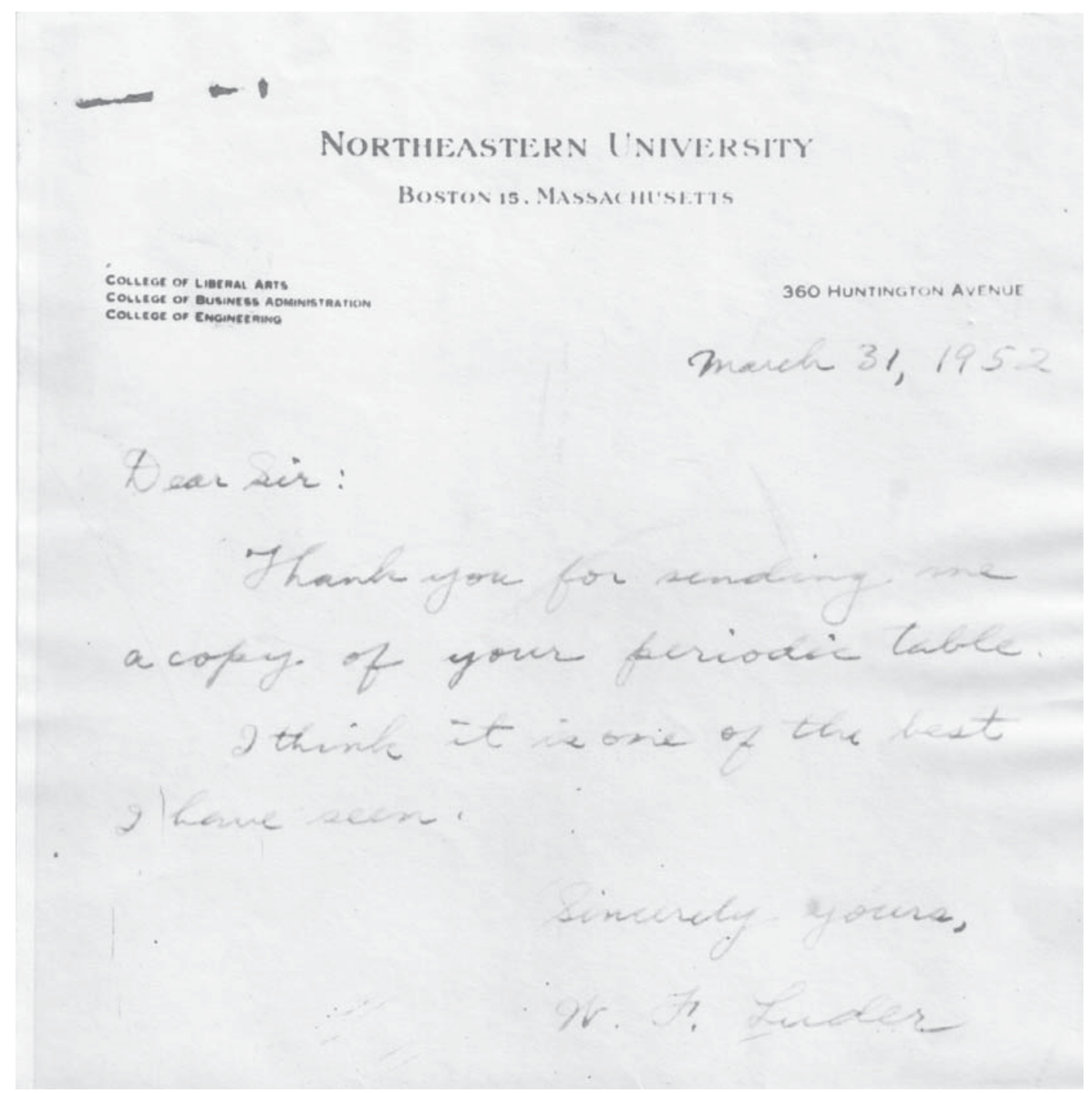

Figura 7. Agradecimento e elogio de W. F. Luder, da Northeastern University. 


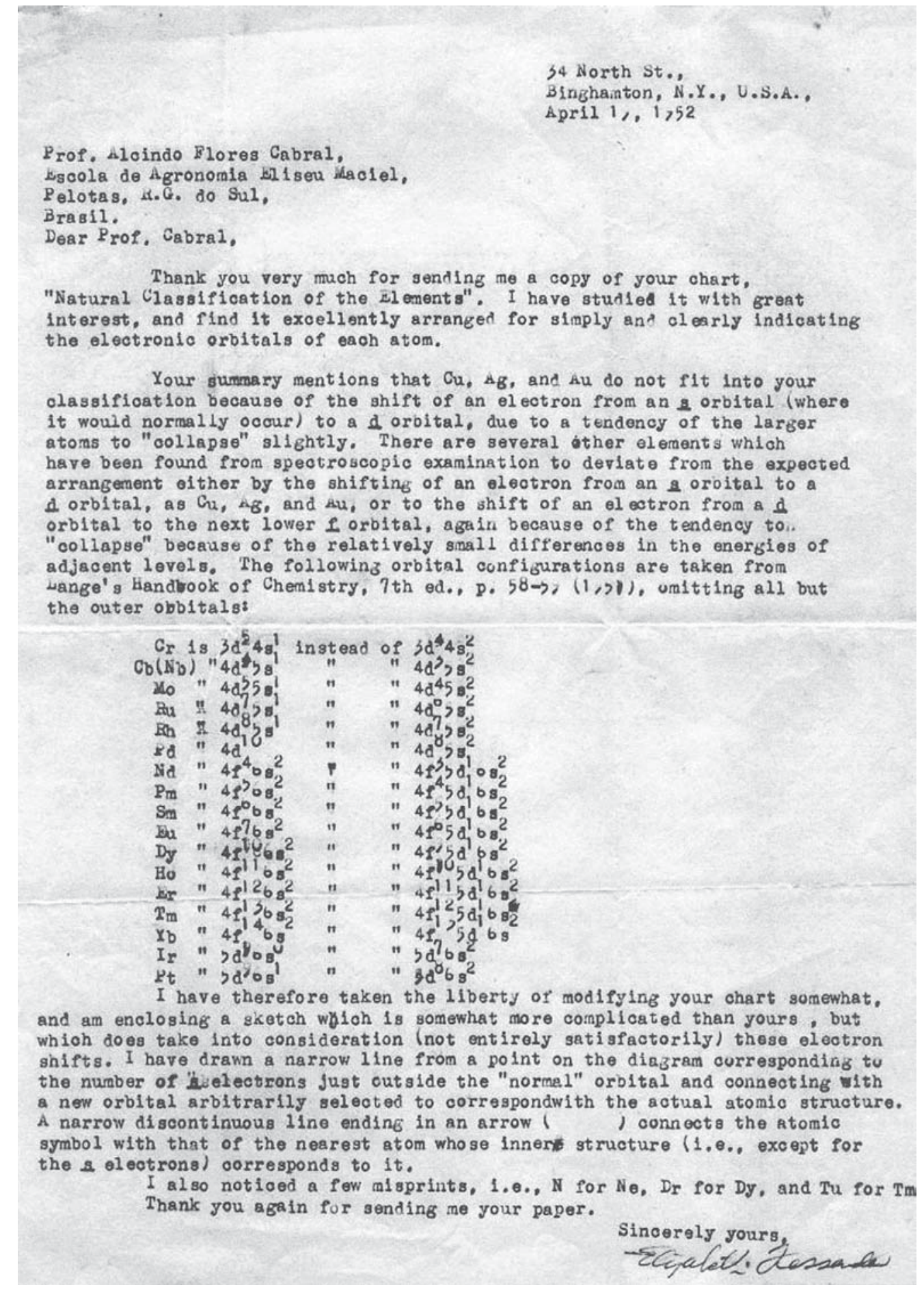

Figura 8. Críticas e sugestões da Professora Elisabeth Fessenden ao professor Cabral (Fonte: H. M. Cabral). 
A gontribuição brasileira de Algindo Flores Cabral...

"ideia de oscilação de elétrons entre orbitais de átomos diversos" (1953b, p. 11, grifo nosso), Cabral desenvolveu estruturas dinâmicas para compostos mesoméricos, extremamente claras e úteis para mostrar a interação por ressonância entre elétrons de átomos diferentes. Na apresentação de seu livro, após algumas considerações sobre a valência dos átomos, Cabral faz a seguinte dedicatória:

\begin{abstract}
nesse centenário do nascimento do Sábio de Rotterdam (van't Hoff) $\mathbf{5}$ apresentamos, em sua homenagem, o presente estudo das valências duplas e triplas, bem como das formas mesoméricas (...) cujas origens vão se encontrar num princípio estabelecido por van't Hoff: livre rotação do carbono em torno das ligações simples (Cabral, 1953b, p. 4).
\end{abstract}

Finalmente, em 1958, Cabral publicou Elementos de química eletrônica, definido pelo autor como um procedimento de exposição didática racional, simplificando e sistematizando a química inorgânica, de acordo com as teorias modernas (para a época). Nesse livro, de 1411 páginas, Cabral acrescenta aos conceitos desenvolvidos até aquela época suas contribuições, como a classificação natural dos elementos (um desenho do gráfico acompanhava o livro) e suas estruturas dinâmicas para a representação de compostos insaturados. No capítulo que trata da sistematização dos compostos inorgânicos, Cabral divide os elementos em quatro grupos, chamando-os de "grupos naturais", e discutindo-os de acordo com sua Classificação natural dos elementos. Alguns de seus trabalhos foram reeditados várias vezes, na forma de "boletins didáticos" amplamente utilizados ao longo do curso de graduação em engenharia agronômica da Escola de Engenharia Eliseu Maciel.

\title{
6 Uma Grítica À obra LÍtero-Didática de Cabral
}

O professor Alcindo Cabral, como entusiasta da divulgação e do ensino da química, não deixou uma obra experimental original, pois suas atividades práticas parecem ter sido análises e ensaios de rotina. Assim, sua obra é exclusivamente literária, destinada, confessadamente, a facilitar a aprendizagem da química por não químicos, e é sob esse prisma que seus textos devem ser examinados. Se Cabral faz passar por modernos conceitos que já não o eram quando sobre eles escreveu, como a acidez de Brönsted e Lowry, conceitos sobre os quais escreveu em 1953, mas que já datavam de 1923, deve-

5 Coincidentemente, van’t Hoff formulou sua hipótese do carbono tetraédrico enquanto professor da Escola de Veterinária de Utrecht. 
se ter em mente que anacronismos dessa ordem ou, em outras palavras, o atraso observado em textos didáticos em relação ao conhecimento atualizado da época em que foram escritos, não é um defeito nem de Cabral, nem de sua época, nem da química, e tampouco do meio acadêmico brasileiro. Cabral é apenas mais um nome na galeria dos autores brasileiros de textos didáticos nos quais tal tendência é regra e não exceção.

Esse tema, sem dúvida importante, de textos desatualizados para o ensino de química foi analisado de modo detalhado por Mortimer. No entender de Mortimer, o problema da desatualização torna-se agudo no início do século xx, pois "[o período] que corresponde ao século xix apresenta livros muito atualizados, cujos autores discutem em pé de igualdade com os cientistas europeus, o significado de novos conceitos" (Mortimer, 1988, p. 32). Incluem-se ali a polêmica dualismo-unitarismo, das valências constantes ou variáveis, e a hipótese do carbono tetraédrico de van't Hoff e Le Bel, que já se encontra em textos da década de 1880. Tal situação, segundo Mortimer, mudaria a partir de inícios do século xx, e os motivos seriam essencialmente dois. Por um lado, uma certa inércia dos textos didáticos, "não conseguindo acompanhar a evolução vertiginosa dos conhecimentos, neste começo de século" (Mortimer, 1988, p. 26) e, por outro lado, a "dificuldade em abandonar teorias e conceitos ultrapassados" (Mortimer, 1988, p. 26-7). Exemplos desse segundo fator são a definição de elemento, a teoria atômica ignorando um caráter nuclear e quantizado, ou a distinção correta entre covalência e eletrovalência. Por volta de 1930, ocorreram, segundo Mortimer, prenúncios de atualização, mas esta continuaria extremamente lenta, e, "desse modo, os livros vão chegar ao final da década de 1950 bastante desatualizados” (p. 32).

Para além dessa análise de Mortimer, procurando também as razões da desatualização, há a crítica mais ácida e inflexível de Rheinboldt (1994), que nos anos 50, historiando a evolução da química no Brasil, tece comentários dos textos didáticos aqui produzidos. Para mostrar que a perspectiva didática de Cabral não é um fato isolado da redação de textos didáticos de química, consideraremos aqui algumas das críticas de Rheinboldt. Merece-lhe especial repulsa a obra de Tibúrcio Valeriano Pecegueiro do Amaral (1864,-1944), professor de química da Faculdade de Medicina do Rio de Janeiro, cujo texto Elementos de chimica inorganica de 1907 é considerado "péssimo" (Rheinboldt, 1994, p. 45). Por exemplo, representa o ácido sulfúrico à maneira de Kekulé como H-O-O-S-O-O-H e, na edição modernizada de 1930, desconhece a síntese da amônia de Haber-Bosch. O que mais irrita Rheinboldt é o fato de ninguém ter criticado a omissão, que está presente ainda na edição de 1934 (Rheinboldt, 1994, p. 46). Por outro lado, o compêndio Elementos de chimica organica, de 1900, parece aceitável a Rheinboldt, embora utilizasse indistintamente fórmulas estruturais e a teoria dos tipos (p. 44). Se na então capital da República produziam-se textos tidos como superados, o que dizer de textos produzidos em rincões distantes? Não se pode, contudo, es- 
quecer que Heinrich Rheinboldt (1891-1955), representante típico da "química orgânica clássica alemã”, está ele próprio desatualizado no que se refere à abordagem da química orgânica de acordo com as novas teorias eletrônico-estruturais, surgidas afinal na década de 1930. Isso relativiza sua crítica.

Voltando a Mortimer, os livros didáticos desatualizados "atestam o atraso e a dificuldade de atualizar-se o ensino de química no Brasil” (Mortimer, 1988, p.32). Voltando a Cabral, ele se enquadra nesse contexto, e se o "moderno" de algumas de suas abordagens não é realmente moderno, pelo menos ele passa a incluir nos textos desatualizados alguns fatos até então totalmente marginais. O que mais valoriza o mestre de Pelotas, de certa forma um químico "leigo" por formação, é sua preocupação didática de informar a outros "leigos" - estudantes de agronomia e veterinária e o público não universitário - sobre a química. Nessa tentativa, Cabral empreende uma reflexão, talvez não tão ousada como ele pretendia, mas certamente com entusiasmo - sobre alguns dos problemas importantes da química moderna e não tão moderna. Realizou seu trabalho distante dos núcleos da pesquisa química do Brasil da época. Incógnito e esquecido, como na máxima de Marco Aurélio. Há, no Brasil, outros exemplos a serem salvos da grande amnésia que toma conta de nosso patrimônio científico.

\section{A GLASSifiGaÇÃo NATURAL dos ELEMENTOS}

A lei periódica contribuiu decisivamente para o desenvolvimento da química, e a perenidade da tabela concebida inicialmente por Mendeleiev (1869), Lothar Meyer e outros manteve-se mesmo com o advento da mecânica quântica e da teoria quântica. Entretanto, com alguma frequência têm aparecido na literatura artigos demonstrando a insatisfação dos químicos, especialmente educadores, com a forma mais amplamente aceita e difundida da tabela periódica. Centenas de desenhos diferentes da tabela foram descritos ao longo dos anos, procurando arranjar os elementos de tal forma que a periodicidade de suas propriedades fosse melhor entendida. ${ }^{6}$ Da mesma forma que a finalidade de uma tabela periódica pode variar, seu desenho, ou seu registro gráfico,

6 Desenhos de cerca de 700 representações gráficas diferentes da tabela periódica podem ser obtidos em Mazur (1974). Centenas de formatos diferentes da tabela periódica podem ser acessados através da internet. Os seguintes endereços apresentam links para diversas páginas sobre o assunto: <http://chemlab.pc.maricopa.edu/periodic/ periodic.htm> e Periodical Tables of Historical Interest em <http://www.chemistrycoach.com/periodic_tables.html $>$. Para se ter uma ideia do número de publicações envolvendo representações da tabela periódica alternativas à de Mendeleiev uma busca no Journal of Chemical Education, em abril de 2003, mostrou mais de 40 publicações sobre a tabela periódica entre 1924, (quando a revista foi lançada) e meados da década de 1950, quando Cabral publicou seu trabalho. 
pode variar correspondentemente. Como cada desenho da tabela periódica constitui apenas uma de muitas possibilidades, a questão principal ao analisar as diferentes representações gráficas está em definir qual desenho é útil para determinada situação (cf. Sanderson, 1964). 7

Como vimos, entre as variações propostas para a tabela clássica de Mendeleiev, há várias propostas com arranjo em espiral, circular ou semicircular do sistema periódico (ver as figuras 3). Entretanto, como bem observou Strong em 1959, a maioria das representações em espiral do sistema periódico descritas até então era constituída basicamente pela longa e conhecida tabela periódica "torcida" até adquirir a forma de um círculo. Assim, apesar de sua utilidade didática, não se poderia dizer que eram originais, pois nada acrescentavam efetivamente à maneira de observar e compreender as informações contidas na tabela periódica.

Desconsiderando as primeiras representações em espiral, como as de Hinrichs ou Baumhauer (ver as figuras 1 e 2), talvez o mais conhecido e reproduzido arranjo de um sistema periódico em espiral e/ou circular seja a forma atômica da tabela periódica do próprio Strong (ver a figura 3e), publicada em 1959, e depois revisada e atualizada em 1985 (cf. Strong, 1985). Outras representações desse tipo foram as de Monroe e Turner (1926), de Zmaczynski (1937), de Emerson (1944) e de Griff (1964). Em seu artigo de 1959, Strong cita a Classificação natural dos elementos do Professor Cabral (ver as figuras $3 \mathrm{~d}, 4 \mathrm{e} 5$ ) como sendo a primeira correlação entre a estrutura atômica e uma tabela em círculos concêntricos, e não apenas mais um novo arranjo geométrico.

O primeiro esboço da Classificação natural dos elementos foi elaborado em janeiro de 1946 (ver as figuras 3d e 4b). Preocupado com a qualidade de suas aulas, ele se mantinha constantemente atualizado sobre os avanços da química na primeira metade do século xx, e percebendo possivelmente a dificuldade em ensinar química para não químicos (pois ele próprio não era formado em química), desenvolveu uma maneira inovadora de representação dos elementos químicos, a forma visual da estrutura atômica. Embora a mesma tenha sido mais tarde aperfeiçoada por outros e por ele próprio. Considerava que o uso de cores diferentes para representar os subníveis $s, p, d$ ef foi um valioso aperfeiçoamento (cf. Cabral, 1951), sugerido por um aluno, C. L. Alves da Fonseca, em 1949 (ver as figuras 4 b e 5). Até onde é de nosso conhecimento, não se sabe quando e por quem foi utilizado pela primeira vez o sistema periódico no Brasil, a criação do professor Cabral foi certamente um marco no ensino de química em nosso país, constituindo-se em uma contribuição valiosa na busca por uma representação mais didática da periodicidade química.

7. Para uma excelente discussão sobre as múltiplas formas de apresentar a lei periódica e suas implicações epistemológicas e pedagógicas, ver Mishra e Nguyen-Jahiel (1997). 
Na apresentação de seu trabalho, Cabral escreve que seu gráfico "não é uma simples classificação de Mendelejeff em forma circular, pois a ideia básica da sua coordenação é a do elétron diferenciador" (Cabral, 1951, p. 3). Cabral inspirou-se na proposta de Ebel, que sugeriu a construção de uma tabela periódica com base na estrutura atômica e introduziu o termo "elétron diferenciador" para designar o elétron que diferencia um átomo de seu antecessor na tabela (cf. Ebel, 1938). Na Classificação natural dos elementos (ver a figura 5 ), o símbolo de cada elemento representa, ao mesmo tempo, um elétron, permitindo a obtenção esquemática do desenvolvimento do número de Moseley (número atômico, Z) em um diagrama dos níveis quânticos de Bohr. Nesse sistema, os níveis quânticos de energia ( $n$ ) estão representados pelas circunferências pretas, enquanto que a progressão da faixa colorida, a partir do centro, indica os subníveis $(l)$ em que se situam os elétrons, um a um, à medida que o átomo aumenta de tamanho.

Considerado por Cabral como sendo seu principal trabalho, a Classificação natural dos elementos teve boa aceitação frente aos poucos membros da comunidade química que na época tiveram acesso a sua obra. Como não publicou seus trabalhos em revistas científicas de circulação internacional, sua obra é praticamente desconhecida, mesmo no Brasil.

Alcindo Cabral utilizou uma forma bastante inusitada de divulgar seus trabalhos. Em 1961, elaborou o Boletim Didático n. 1, contendo a apresentação de seu gráfico em português, seguida de um abstract em inglês. Uma cópia colorida da Classificação natural foi anexada ao texto. Ciente do valor de seu trabalho, enviou uma cópia do livreto a um grupo seleto de cientistas norte-americanos e europeus, alguns dos quais tinham publicado na época artigos sobre a lei periódica ou sobre a tabela periódica. Leitor assíduo do Journal of Chemical Education, dali selecionou alguns dos nomes que receberiam seu trabalho, como W. F. Luder, R. T. Sanderson, Robert L. Ebel, entre outros. Autores renomados de livros-texto de química da época também foram contemplados: Gaston Charlot (1904-1994), Walter Hückel (1895-1973), Elisabeth Fessenden, entre outros. Pouco tempo depois Cabral passou a receber vários pedidos de cópias de seu trabalho. As figuras 6 e 7 mostram dois pedidos de separatas e comentários selecionados entre os cerca de 20 documentos aos quais tivemos acesso. Essa maneira pouco convencional de divulgação, se, por um lado, fez com que alguns cientistas de países desenvolvidos conhecessem seu trabalho, por outro, provocaram o ostracismo e esquecimento do professor Cabral, pois poucas pessoas tiveram acesso a suas publicações. ${ }^{8}$

$8 \mathrm{Um}$ dos autores do presente artigo (JHM) estudou química na Universidade Federal do Rio Grande do Sul no período 1964-1968, e na época não ouvira de seus professores referências à classificação do professor Cabral, que se aposentara em Pelotas em 1966. 
Várias sugestões e algumas discussões sobre o seu gráfico também ocorreram na correspondência de Cabral com colegas educadores do país e do exterior (veja-se, como exemplo, a figura 8). Apesar de algumas críticas recebidas, especialmente o fato de ocuparem os elementos de transição posições diferentes das previstas em função das suas distribuições eletrônicas, parece ter havido um consenso quanto ao valor da inovação introduzida por Cabral, especialmente se considerarmos o fato de o Brasil praticamente inexistir perante a comunidade química internacional da época.

\section{Conclusẽ̃o}

Embora para muitos químicos a forma longa da tabela periódica apresente-se como a única estrutura organizacional possível para os elementos químicos, fruto da adoção desse formato pela quase totalidade dos livros didáticos, há centenas de maneiras diferentes de representá-la, e todas podem ser adequadas para determinadas situações. Ao apresentar sua representação gráfica no Boletim Didático $\mathrm{n}^{0}{ }_{1}$, Cabral escreveu tratar-se de um gráfico "tão claro e elucidativo que parecia estar destinado à ampla aceitação e emprego pelos que se dedicam à química, tanto no terreno didático como no técnico, em vista da importância primacial que as publicações mais recentes dão aos orbitais atômicos para o conhecimento da valência" (Cabral, 1951, p. 4). Como sabemos, isso não aconteceu. Há quase 60 anos, no extremo sul do Brasil, um professor de química criou uma nova e atraente maneira de mostrar a seus alunos a periodicidade química. Seus trabalhos didáticos sobre ligações químicas e distribuição eletrônica podem ser considerados como contribuições importantes para a melhoria do ensino de química, se analisarmos as desatualizações no contexto da produção brasileira de textos como um todo. Esperamos que o presente artigo possa instigar os colegas da área da química a repensar a maneira como é ensinada a lei periódica (cf. Ceccon \& Berner, 1967) e outras teorias já bastante solidificadas, porém de difícil compreensão para alunos de graduação e do ensino médio. Por outro lado, a Classificação natural dos elementos é apenas uma das contribuições de Alcindo Cabral para o ensino de química, uma contribuição que por sua importância histórica única na química brasileira merece ser resgatada e mostrada à comunidade científica nacional. Fica mais uma vez demonstrado, como tantas vezes ocorreu na nossa ciência, que um meio desfavorável impede o pleno desenvolvimento de ideias originais e criativas por parte de talentos promissores.

Agradecimentos. Os autores agradecem ao senhor Heleno M. Cabral e à Professora Maria de Fátima Butierres (CCQFA/ UFPEL) pelo gentil fornecimento de grande parte do material consultado. Agradecem igualmente à FAPERGS e ao CNPq por auxílios concedidos. 
Juergen Heinrich MAAR Associação Filosófica Scientiae Studia, São Paulo. Professor aposentado do Departamento de Química, Universidade Federal de Santa Catarina, Brasil. jhmaar@yahoo.com.br

\section{Eder João LENARDÃo}

Centro de Ciências Químicas, Farmacêuticas e de Alimentos, Universidade Federal de Pelotas, Campus Capão do Leão, Brasil. lenardao@ufpel.tche.br

\section{AB STRACT}

This paper presents the contributions of Alcindo Flores Cabral (1907-1982), professor of chemistry at the Faculdade de Agronomia Eliseu Maciel, nowadays part of the Universidade Federal de Pelotas, to chemistry teaching, a contribution almost unknown to the Brazilian chemical community, although recognized as valuable by several renowned chemists abroad, such as W. Hückel, G. Charlot, F. Strong, E. Fessenden and others. Cabral's innovative helicoidal representation is presented not only in connection not only with contemporary representations, but it also includes an incursion into the first helicoidal systems proposed, those of Hinrichs and of Baumhauer. Some comments are made on Cabral's Classificação natural dos elementos, published in 194,6, and also on other texts that he wrote to make chemistry teaching more effective.

KeYwords $\bullet$ Periodic table. Natural classification of elements. History of chemistry in Brazil. Cabral.

\section{REFERÊNGIAS BIBLIOGRÁFIGAS}

Azevedo, F. As ciências no Brasil. 2. ed. Rio de Janeiro: Editora da Universidade Federal do Rio de Janeiro, 1994 .

Bertomeu-Sanches, J. R. et al. Looking for an order of things: textbooks and chemical classification in 19th century France, Ambix, 49, p. 227-50, 2002.

Cabral, A. F., Ensaio de teoria eletrônico-molecular. Pelotas: Escola de Agronomia Eliseu Maciel, 194_o. . Classificação natural dos elementos. Pelotas: Editora Instituto Agronômico do Sul, 1946. . Classificação natural dos elementos. Pelotas: Editoria da Escola de Agronomia Eliseu Maciel, 1951. . A teoria de ácidos e bases de Arrhenius e as ideias modernas. Pelotas: Editora da Escola de Agronomia Eliseu Maciel, 1953a. - A representação gráfica de alguns sistemas complexos de conexões atômicas. Pelotas: Editora da Escola de Agronomia Eliseu Maciel, $195^{3 \mathrm{~b} .}$

Elementos de química eletrônica. Pelotas: Editora da Escola de Agronomia Eliseu Maciel, 1958.

CAнn, R., Historische und Philosophische Aspekte des Periodensystems der Chemischen Elemente. Karlsruhe: Hyle, 2002. 
Cegcon, O. \& Berner, R. Classificação periódica dos elementos. Monografia Didática. Universidade Federal do Paraná, Curitiba, 1967.

Ebel, R. I. Atomic structure and the periodic table. Journal of Chemical Education, 15, p. 575-7, 1938.

Emerson, E. I. A new spiral form of the periodic table. Journal of Chemical Education, 21, p. 111-5, 1944 .

GrifF, H. K. A clockwise spiral system of the chemical elements. Journal of Chemical Education, 41, p. 191, 1964 .

Hirsig, R. Systemtheorie. Universitaet Zuerich: Psychologisches Institut, 1994. Disponível em: <ftp:// ftp.geoinfo.tuwien.ac.at/wilke/BUP_skriptsam>. Acesso em: 02 nov. 2008.

Ihde, A. The development of modern chemistry. Nova York: Dover, 1984.

Leon Olivares, F. Syntex, una historia mexicana y su divulgación en el Bachillerato. Educación Química, 12 , p. $175^{-} 78,2001$.

Magalhães, M. O. Faculdade de Agronomia Eliseu Maciel. 2 ed. Pelotas: Universidade Federal de Pelotas, 1996.

MAZUr, K. Graphic representations of the periodic system during one hundred years. Tuscaloosa: University of Alabama Press, 1974 .

Monroe, C. J. \& Turner, W. D. A new periodic table of the elements. Journal of Chemical Education, 3, p. $105^{8-65}, 1926$.

Mishra, P. \& Nguyen-Jahiel, K. Multiple visual representations of the periodic system of elements: epistemological and pedagogic implications. Proceedings of the 1997 International Visual Literacy Association Conference. Pensylvania: State College, 1997. Disponível em: <http://punya.educ.msu.edu/PunyaWeb/ pubs/print/periodic-jvla/periodic-jvla.pdf >. Acesso em: 20 abr. 2003.

Mortimer, E. A evolução didática dos livros de química destinados ao ensino secundário. Em Aberto INEP-MEC, 4, , p. 25-4,1, 1988.

Renatus, E. Julius Quaglio (1833-1899) und die Geschichte des Periodensystems. Chemie in Unserer Zeit, 17, p. 96-102, 1983.

Rheinboldt, H. A química no Brasil. In: Azevedo, F. As ciências no Brasil. 2 ed. Rio de Janeiro: Editora da Universidade Federal do Rio de Janeiro, 1994. v. 2.

SAnderson, R. T. The proper place for hydrogen in the periodic table. Journal of Chemical Education, 41, p. $187-89,1964$.

Scerri, E. The periodic table and the electron. American Scientist, 85, p. 54,6-53, 1997. . The evolution of the periodic system. Scientific American, 279, p. 78-83, 1998.

Spronsen, J. W. van. The pre-history of the periodic system. Journal Chemical Education, 36, p. $5^{6} 5^{-} 7$, 1959.

The periodical system of chemical elements. Amsterdam: Elsevier, 1969.

Strong, F. C. The atomic form periodic table. Journal of Chemical Education, 36, p. 344- ${ }^{-5}, 1959$.

Revised atomic form periodic table. Journal of Chemical Education, 62, p. 456, 1985.

ZAPpfe, C. Gustavus Hinrichs, precursor of Mendeleev. Isis, 6o, p.461-76, 1969.

Zmaczynski, E. W. Periodic system of the elements in a new form. Journal of Chemical Education, 14, p. $232-5,1937$.

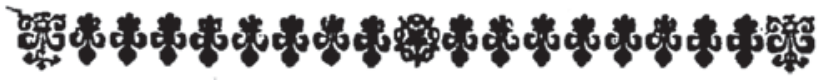

